\title{
Prevalence and antibiotic resistance of Pseudomonas aeruginosa isolated from swimming pools in northern Greece
}

I. Tirodimos, ${ }^{1}$ M. Arvanitidou, ${ }^{1}$ T. Dardavessis, ${ }^{1}$ A. Bisiklis ${ }^{2}$ and S. Alexiou-Daniil ${ }^{2}$

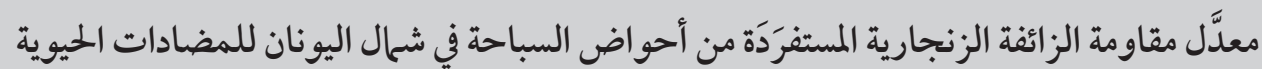

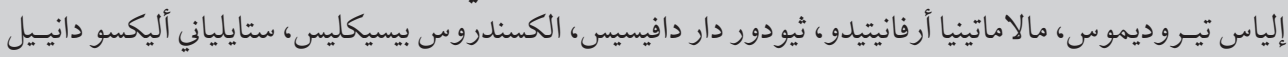

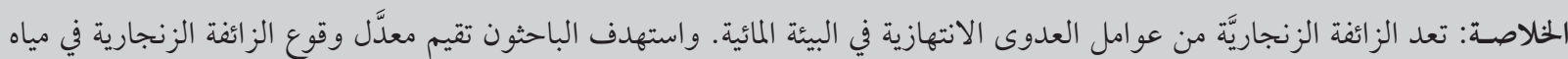

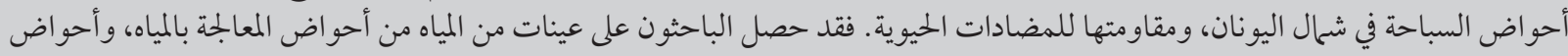

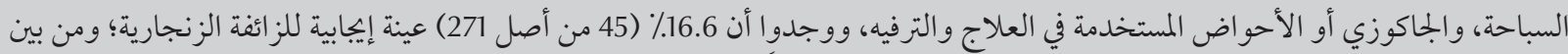

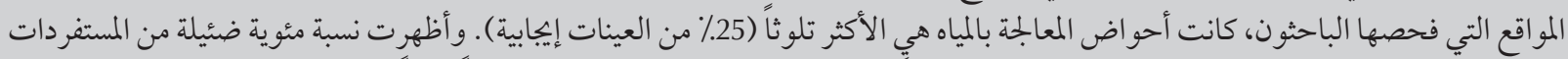

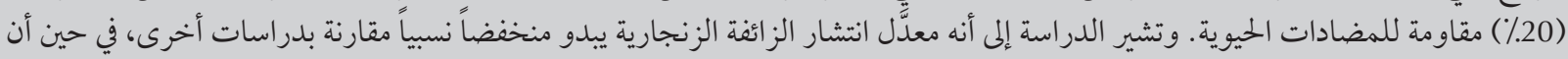

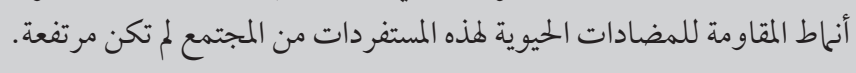

ABSTRACT Pseudomonas aeruginosa is an important agent of opportunistic infection in aquatic environments. Our aim was to evaluate the occurrence and antimicrobial resistance of $P$. aeruginosa in the water of swimming pools in northern Greece. Water samples were obtained from hydrotherapy pools, jacuzzis/spas and swimming pools. A total of $16.6 \%(45 / 271)$ of the samples were positive for $P$. aeruginosa. Of the amenities examined, the most contaminated were hydrotherapy pools (25\% of samples positive). A small percentage of isolates (20.0\%) showed resistance to antibiotics. Compared with other studies, the prevalence of $P$. aeruginosa in swimming pools was relatively low, while the antibiotic resistance pattern of these community isolates was not high.

Prévalence et résistance antibiotique de Pseudomonas aeruginosa isolé dans des piscines du nord de la Grèce

RÉSUMÉ Pseudomonas aeruginosa est un agent d'infection opportuniste fréquent, qui prolifère dans les environnements aquatiques. Notre objectif était d'évaluer la présence et la résistance de $P$. Aeruginosa aux antimicrobiens dans l'eau de piscines situées dans le nord de la Grèce. Des échantillons d'eau provenant de bassins d’hydrothérapie, de jacuzzis/spas et de piscines ont été prélevés. Au total, 16,6 \% des échantillons(45/271) étaient positifs à $P$. Aeruginosa. Les bassins d'hydrothérapie étaient les plus contaminés des équipements analysés, (25\% des échantillons étaient positifs). Un faible pourcentage d'isolats $(20,0 \%)$ a révélé une résistance aux antibiotiques. En comparaison avec d'autres études, la prévalence de $P$. Aeruginosa dans les piscines était relativement faible, et le profil d'antibiorésistance de ces isolats communautaires était peu élevé.

'Laboratory of Hygiene; '2Laboratory of Microbiology, AHEPA Hospital, Medical School, Aristotle University of Thessaloniki, Thessaloniki, Greece (Correspondence to I. Tirodimos: iltirodimos@yahoo.gr).

Received: 05/11/08; accepted: 27/11/08 


\section{Introduction}

Pseudomonas aeruginosa belongs to a vast genus of obligate aerobic, nonfermenting, saprophytic, Gram-negative bacilli widespread in nature, particularly in moist environments such as water, sewage, soil, plants and animals [1]. The organism is able to grow and multiply in a variety of water sources including river water, seawater, wastewater and bottled mineral water $[2,3]$.

$P$. aeruginosa is an important agent of opportunistic infection in patients, particularly in those with respiratory complications and burns. According to Craun et al., Pseudomonas spp. was one of the most frequently identified agents associated with waterborne outbreaks of dermatitis (rash or folliculitis), as well as conjunctivitis, otitis externa and other symptoms, in recreational water in the United States of America (14\%) [4]. Pseudomonads are well adapted to survival in whirlpools, hot tubs and indoor pools because of the warm water temperatures. These waters are especially prone to contamination during periods of high use when it is difficult to maintain adequate disinfection levels.

Although recreational water is a documented environmental source of $P$. aeruginosa, there are limited published data about the prevalence of this organism in swimming pools, saunas and hot tubs $[5,6]$. In this study, we aimed to identify the prevalence of $P$. aeruginosa in recreational water facilities in northern Greece and to examine the correlation of $P$. aeruginosa with standard faecal pollution indicator bacteria. We also used antibiograms as an epidemiological marker for our P. aeruginosa isolates in view of the fact that antibiotics are cheap and easily available without prescription to the Greek population, creating a risk of antibiotic-resistant strains emerging [7].

\section{Methods}

\section{Sampling}

The Laboratory of Hygiene is the government reference centre for assessing the chemical and bacteriological quality of potable and recreational waters for the area of northern Greece (Macedonia and Thrace). In the 1-year period 2005, 271 recreational water samples were sent from the local health authorities and other public services to our laboratory. The samples were obtained from 3 amenity categories, namely 4 hydrotherapy pools ( $n=8$ samples), 4 jacuzzis/spas ( $n=49$ samples) and 21 swimming pools ( $n=214$ samples). Samples were taken in sterilized darkcoloured 1-litre bottles containing chloride scavenger and were kept refrigerated at a temperature of $4^{\circ} \mathrm{C}$ before microbiological analyses

\section{Microbiological analyses and antibiotic susceptibility testing}

Total heterotrophic bacteria were counted on plate count agar using $1 \mathrm{~mL}$ infusion technique after incubation at $37^{\circ} \mathrm{C}$ for $48 \mathrm{~h}$. For total coliforms, the $100 \mathrm{~mL}$ membrane filtration technique was used, with $\mathrm{m}$-Endo medium at $3^{\circ} \mathrm{C}$ for $24 \mathrm{~h}$. For Escherichia coli, the $100 \mathrm{~mL}$ membrane filtration technique was also used, with tryptone bile X-glucuronide agar at $44.5^{\circ} \mathrm{C}$ for $24 \mathrm{~h}$.

$P$. aeruginosa was confirmed by the Vitek2 automated microbiology system (bioMérieux, Marcy l’Etoile, France). The minimum inhibitory concentrations (MIC) of antibiotics were determined by broth microdilution assay on the Vitek 2 system. MICs were interpreted according to the 2004 criteria of the National Committee on Clinical Laboratory Standards (NCCLS) [8].P. aeruginosa (ATCC 27853) was used as the quality control strain. The antibiotics used were selected according to the 2004 NCCLS guidelines: amikacin, aztreonam, cefepime, ceftazidime, ciprofloxacin, gentamicin, imipenem, meropenem, piperacillin, ticarcillin + clavulanic acid and tobramycin. The MICs of an isolate resistant to carbapenems (imipenem and meropenem) were further confirmed by the epsilometer test (AB Biodisk, Solna, Sweden).

\section{Statistical analysis}

Data analysis was performed using the statistical package SPSS for Windows, version 14.0. The chi-squared test was used at $5 \%$ significance level.

\section{Results}

Measurements of some important health-related microbiological parameters and the prevalence of $P$. aeruginosa are given on Tables 1 and 2 .

A total of 271 water samples from 3 amenity categories $(n=29)$ were obtained (Table 1). Of the samples examined 39/214 from swimming pools (18.2\%), 4/49 from jacuzzis/spas $(8.2 \%)$ and $2 / 8$ from hydrotherapy pools (25\%) were positive for $P$. aeruginosa (total 45/271, 16.6\%). The highest isolation rate of P. aeruginosa (25.0\%) was from hydrotherapy pools. However, no significant differences were found between different amenity categories in the rate of isolation of pseudomonads or the median number of colony-forming units of $P$. aeruginosa per $100 \mathrm{~mL}$ $(P>0.05)$ (Tables 1 and 2).

According to Greek regulations, the microbiological quality of the water samples from the different amenity categories of recreational water was reasonably good, with the exception of hydrotherapy pools (Table 1); 50\% of specimens from hydrotherapy pools were not compliant with the Greek hygiene regulations. The median colony count of faecal coliforms in this amenity was also by far the largest at 30.5 per 100 $\mathrm{mL}$ (range 1-100) (Table 2). There was therefore a significant difference among the different categories of amenity in the rate of compliance with standards $(P<0.05)$. 


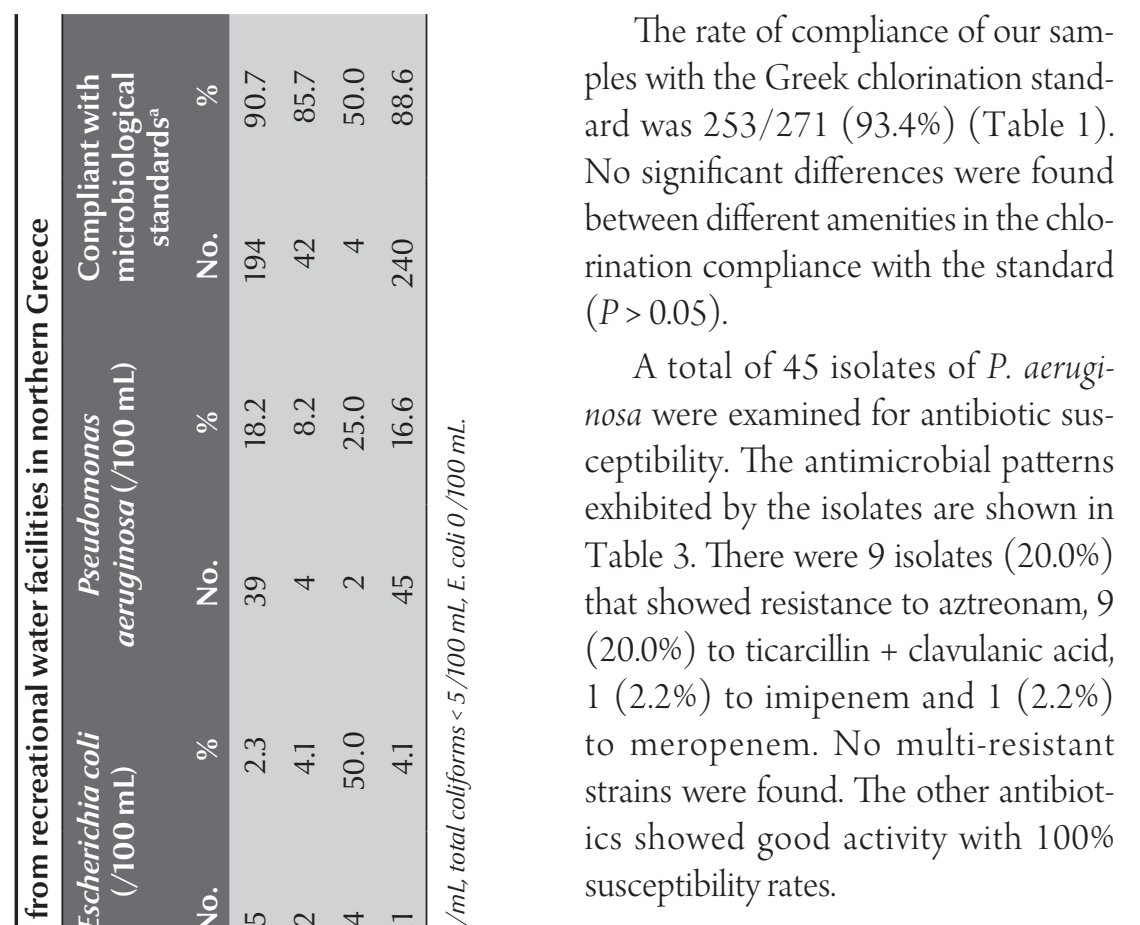

\section{Discussion}

In this study we found that the prevalence of $P$. aeruginosa in swimming pools and recreational waters in northern Greece was $16.6 \%$. So far, only a few studies have examined the prevalence of $P$. aeruginosa in recreational waters. Our results are close to these obtained from a survey in the Athens area (17\% prevalence) [9]. However, a study from Ireland reported a very high prevalence of $P$. aeruginosa in $38 \%$ of swimming pools and $73 \%$ of jacuzzis and spas, while another study from Switzerland showed an overall prevalence of $4 \%[5,6]$. As Barben et al. suggested, the explanation for the widely varying rates of $P$. aeruginosa that have been identified in these studies reflects different approaches to the maintenance of recreational waters [6]. The level of free chlorine, the density of use, poor operation, construction and maintenance of these pools as well as the presence of large plastic inflatables in the pool may affect the prevalence of Pseudomonas spp. [10].

Waterborne outbreaks of conjunctivitis, otitis externa and dermatitis (rashor folliculitis) caused by P. aeruginosa have been reported [10,11]. Pseudomonads are well adapted to survival in pools because of the warm water temperatures, something quite common in Greece. Outbreaks of pseudomonas dermatitis are preventable if water is maintained at a $\mathrm{pH}$ of 2.0-5.0 with free chlorine levels in the range of $2.0-5.0 \mathrm{mg} / \mathrm{L}[12]$. Close attention to bather overcrowding, as well as frequent monitoring of disinfectant levels and maintenance of adequate treatment can help prevent these outbreaks.

The rate of compliance of our samples with the Greek chlorination standard was $93.4 \%$. One factor which should be kept in mind is that most pathogens of concern in water recreation and sports are more resistant than coliforms to chlorine. For instance, Staphylococcus spp. and Pseudomonas spp. were found to be many times more resistant to chlorine than coliforms [13]. It is therefore not surprising to recover Pseudomonas spp. in samples from swimming pools in which no coliforms were found.

The 1973 Greek hygiene regulations [14] determining various factors to ensure good water quality in swimming pools of all types are considered obsolete. Standards which are more complete and deal with modern processes such as ozonation include the German standard DIN 19643 Treatment and disinfection of swimming pool and bathing pool water and DIN 19605 Filters for water treatment, as well as the British Blue Book Treatment and quality of swimming pool water [15-17]. Thus, if we use the Greek regulations, 31/271 samples (11.4\%) were non-compliant with sources. However, if we use DIN 19605 which demands absence of $P$. aeruginosa in the microbiological parameters, another 35 samples (12.9\%, a total of $24.4 \%)$ would be non-compliant with standards $(P=0.02)$.

Half of the samples from hydrotherapy pools were non-compliant with Greek hygiene regulations and were also found with a high load of E. coli. Hydrotherapy pools in Greece are popular facilities used mainly by the elderly and 


\begin{tabular}{|c|c|c|c|c|}
\hline \multirow[t]{2}{*}{ Water category } & \multicolumn{4}{|c|}{ Median no. of colonies $(\min -\max )^{a}$} \\
\hline & Total heterotrophic bacteria & Total coliforms & Escherichia coli & Pseudomonas aeruginosa \\
\hline Swimming pools $(n=214)$ & $20(2-3000)$ & $4(1-50)$ & $2(1-16)$ & $14(0-100)$ \\
\hline Jacuzzis/spas $(n=49)$ & $20(2-3000)$ & $4(2-40)$ & $4(1-7)$ & $10(1-80)$ \\
\hline Hydrotherapy pools $(n=8)$ & $20(10-48)$ & $2(1-120)$ & $30.5(1-100)$ & $11.5(3-20)$ \\
\hline Total $(n=271)$ & $20(2-3000)$ & $4(1-120)$ & $2(1-100)$ & $12(0-100)$ \\
\hline
\end{tabular}

${ }^{a}$ Median is shown due to the statistically abnormal distribution of the sample.

$\mathrm{n}=$ no. of samples analysed.

sick people. These people have a low level of hygiene education and are very prone to faecal accidents. When these characteristics are combined with overcrowding, contamination of pools is very likely. Training of hydrotherapy pool managers, operators and staff should include information about the transmission of waterborne illnesses and the critical role of treatment, operation/maintenance and monitoring in preventing these illnesses.

$P$. aeruginosa is naturally resistant to many antibiotics because of their relatively impermeable membrane, constitutively expressed and inducible efflux systems and a chromosomally encoded inducible $\beta$-lactamase. These antibiotics include penicillin $\mathrm{G}$, aminopenicillins-even when combined with $\beta$-lactamase inhibitors - and firstand second-generation cephalosporins; $P$. aeruginosa is also naturally resistant to macrolides, chloramphenicol, cotrimoxazole, rifampin, kanamycin and first-generation fluoroquinolones, such as norfloxacin [18]. At this point we must mention that the study of antibiotic resistance in environmental strains is not common and may produce poor results in relation to clinical isolates. In principle, all hospital and household wastewater should be treated before release into the environment. However, sometimes the uncontrolled disposing of antibiotics and chemicals into the environment may create a selective pressure on these drugs. Furthermore, the members of a particular environmental clonal complex may be very successful and widespread in natural as well as in clinical environments, having developed the ability to quickly adapt to noxious substances (antimicrobials, detergents, pesticides, heavy metals) entering their environment [19].
The overall incidence of antibiotic resistance of our isolates was very low compared with clinical isolates [7], while no multi-drug resistant strains were found. All of our isolates (100\%) were susceptible to cefepime, ceftazidime, piperacillin ( $\beta$-lactams), amikacin, gentamicin, tobramycin (aminoglycosides) and ciprofloxacin (fluoroquinolones). The high level of resistance to aztreonam (20.0\%) and ticarcillin + clavulanic acid (20.0\%) has been mentioned in studies with nosocomial isolates [20]. As for ticarcillin + clavulanic acid, in Greece there are no official data regarding the resistant strains of $P$. aeruginosa. However, according to data obtained from the Vitek2 system in AHEPA Hospital in Thessaloniki during the year 2005, $41 \%$ of clinical isolates of P. aeruginosa were resistant to these antibiotics. Furthermore, survey data showed emerging

\begin{tabular}{|c|c|c|c|c|c|c|c|c|c|}
\hline \multirow[t]{2}{*}{ Antibiotic } & \multicolumn{3}{|c|}{ Sensitive } & \multicolumn{3}{|c|}{ Intermediate } & \multicolumn{3}{|c|}{ Resistant } \\
\hline & No. & $\%$ & MIC $(\mu \mathrm{g} / \mathrm{mL})$ & No. & $\%$ & $\mathrm{MIC}(\mu \mathrm{g} / \mathrm{mL})$ & No. & $\%$ & $\mathrm{MIC}(\mu \mathrm{g} / \mathrm{mL})$ \\
\hline Amikacin & 45 & 100.0 & $\leq 16$ & 0 & - & 32 & 0 & - & $\geq 64$ \\
\hline Aztreonam & 36 & 80.0 & $\leq 8$ & 8 & 17.8 & 16 & 1 & 2.2 & $\geq 32$ \\
\hline Cefepime & 45 & 100.0 & $\leq 8$ & 0 & - & 16 & 0 & - & $\geq 32$ \\
\hline Ceftazidime & 45 & 100.0 & $\leq 8$ & 0 & - & 16 & 0 & - & $\geq 32$ \\
\hline Ciprofloxacin & 45 & 100.0 & $\leq 1$ & 0 & - & 2 & 0 & - & $\geq 4$ \\
\hline Gentamicin & 45 & 100.0 & $\leq 4$ & 0 & - & 8 & 0 & - & $\geq 16$ \\
\hline Imipenem & 44 & 97.8 & $\leq 4$ & 0 & - & 8 & 1 & 2.2 & $\geq 16$ \\
\hline Meropenem & 44 & 97.8 & $\leq 4$ & 0 & - & 8 & 1 & 2.2 & $\geq 16$ \\
\hline Piperacillin & 45 & 100.0 & $\leq 64$ & 0 & - & - & 0 & - & $\geq 128$ \\
\hline Ticarcillin/clavulanic acid & 36 & 80.0 & $\leq 64 /<2$ & 0 & - & - & 9 & 20.0 & $\geq 128 / \geq 2$ \\
\hline Tobramycin & 45 & 100.0 & $\leq 4$ & 0 & - & 8 & 0 & & $\geq 16$ \\
\hline
\end{tabular}


resistance to carbapenems [21], as was the case with 2 of our isolates.

In conclusion, our findings revealed the prevalence of $P$. aeruginosa in recreational waters in northern Greece was relatively low and was compliant with established local microbiological standards. The exception was a high level of contamination in hydrotherapy pools which might be attributed to lack of hygiene practice of the bathers and lack of training of technical personnel.

\section{References}

1. Goldberg JB. Pseudomonas: global bacteria. Trends in Microbiology, 2000, 8:55-57.

2. Kimata $\mathrm{N}$ et al. Pseudomonas aeruginosa isolated from marine environments in Tokyo bay. Microbial Ecology, 2004, 47:41-47.

3. Hunter PR. The microbiology of bottled natural mineral waters. Journal of Applied Bacteriology, 1993, 74:345-52.

4. Craun GF, Calderon RL, Craun MF. Outbreaks associated with recreational water in the United States. International Journal of Environmental Health Research, 2005, 15:243-262.

5. Moore JE et al. Incidence of Pseudomonas aeruginosa in recreational and hydrotherapy pools. Communicable Disease and Public Health, 2002, 5:23-26.

6. Barben J, Hafen G, Schmid J. Pseudomonas aeruginosa in public swimming pools and bathroom water of patients with cystic fibrosis. Journal of Cystic Fibrosis, 2005, 4:227-231.

7. Arvanitidou $\mathrm{M}$ et al. Occurrence and antimicrobial resistance of Gram-negative bacteria isolated in haemodialysis water and dialysate of renal units: results of a Greek multicentre study. Journal of Applied Microbiology, 2003, 95:180-185.

8. Performance standards for antimicrobial susceptibility testing 14th informational supplement M100-S14. Wayne, Pennsylvania, National Committee for Clinical Laboratory Standards, 2004.

9. Rigas F, Mavridou A, Zacharopoulos A. Water quality of swimming pools in Athens area. International Journal of Environmental Health Research, 1998, 8:253-260.

10. Tate D, Mawer S. Newton A. Outbreak of Pseudomonas aeruginosa folliculitis associated with a swimming pool inflatable. Epidemiology and Infection, 2003, 130:187-192.

11. Hajjartabar M. Poor-quality water in swimming pools associated with a substantial risk of otitis externa due to Pseu- domonas aeruginosa. Water Science and Technology, 2004, 50:63-67.

12. Levin WC, Stephenson WT, Craun GF. Waterborne disease outbreaks 1986-88. Morbidity and Mortality Weekly Report, 1990, 39(SS-1):1-9.

13. Tosti E, Volterra L. Water hygiene of two swimming pools: microbial indicators. Journal of Applied Microbiology, 1988, 65:87-91.

14. Greek hygienic regulation. Instructions for the construction and operation of swimming pools (G1/442). Athens, Greece, Department of Health, 1973.

15. Filters for water treatment. DIN 19605. Berlin, Germany, Deutsches Institut für Normung, 1975.

16. Treatment and disinfection of swimming pool and bathing pool water. DIN 1964. Berlin, Germany, Deutsches Institut für Normung, 1984.

17. Price TJ, Smith JM. Swimming pool waters: the new Blue Book appreciated and discussed. Environmental Health, 1985, 93(2):31-35.

18. Hancock RE. Resistance mechanisms in Pseudomonas aeruginosa and other nonfermentative gram-negative bacteria. Clinical Infectious Diseases, 1998, 27(Suppl. 1):S93-99.

19. Pirnay JP et al. Pseudomonas aeruginosa displays an epidemic population structure. Environmental Microbiology, 2002, 4:898-911.

20. Van Eldere J. Multicentre surveillance of Pseudomonas aeruginosa susceptibility patterns in nosocomial infections. Journal of Antimicrobial Chemotherapy, 2003, 51:347-352.

21. Mavroidi A et al. Carbapenem-hydrolysing VIM-2 metallo- $\beta$ lactamase in Pseudomonas aeruginosa from Greece. Journal of Antimicrobial Chemotherapy, 2000, 46:1041-1042. 